\title{
Slug Flow Characterisation in Horizontal Annulus
}

\author{
Edem Nsefik Eyo, Liyun Lao*
}

Centre for Thermal Energy and Materials, Energy \& Power, Cranfield University, Bedfordshire, MK43 OAL, UK.

*Corresponding author: 1.lao@ cranfield.ac.uk

\begin{abstract}
In order to characterise slug flows in annuli channels and highlight the effect of the eccentricity on the flow behaviours, experiments were conducted in two horizontal annuli setups (i) concentric and (ii) fully eccentric using air and water as the testing fluids. The range of air and water superficial velocities investigated were $0.45-3.49 \mathrm{~m} / \mathrm{s}$ and $0.15-2.77 \mathrm{~m} / \mathrm{s}$ respectively. Slug parameters measured using conductance probes designed for this study include slug length, translational velocity, slug frequency and slug holdup. It is found that the slug translational velocity is unaffected by the annulus eccentricity, however parameters including slug frequency, slug holdup and slug lengths have a higher value in the fully eccentric annulus when compared with the concentric one. We introduced a new definition of hydraulic diameter, which reconciles the correlation between the dimensionless mean slug length and the mixture velocity of the horizontal annuli with different setups.
\end{abstract}

Keywords: Slug Translational velocity, Slug Length, Slug Holdup, Concentric, Fully eccentric

\section{Introduction}

The simultaneous flow of two-phase gas-liquid mixtures in annulus geometries is becoming prevalent in chemical, nuclear and petroleum industries. In the petroleum industry particularly, the underbalanced drilling technique is employed when exploiting marginal offshore fields. 
During such operations, gas-liquid flow is encountered in vertical, inclined and horizontal annuli. The annulus eccentricity could change during these operations.

Slug flow is observed over a wide range of gas and liquid flow conditions in horizontal, inclined and vertical conduits. The design of multiphase flow equipment and pipelines rely on detailed characterisation of slug flow parameters. Theoretical analysis, experimental measurements and numerical simulations have been undertaken over the years to characterise slug parameters such as slug frequency, slug translational velocity, slug body holdup and slug length ${ }^{1}$.

Due to the importance of two-phase flow in horizontal annuli, many studies have been undertaken to understand the flow hydraulics in such geometries. Studies have been carried out in horizontal annuli by researchers including Salcudean et al., ${ }^{2}$, Osamusali \& $\mathrm{Chang}^{3}$, Omurlu Metin \& Co-workers ${ }^{4,5}$, Osgouei and others ${ }^{6-8}$, Gschnaidtner, ${ }^{9}$ and Nossen et al. ${ }^{10}$. Recently, Eyo \& Lao ${ }^{11}$ presented studies on gas-liquid flow regimes in horizontal annuli. A qualitative description of annular flow regimes were highlighted based on high speed camera recordings and Probability Density Function of liquid holdup obtained by conductance probes. Although slug flow was encountered during their studies, very few studies have been undertaken to characterise slug flow parameters in horizontal annuli geometry. Lage et al., ${ }^{12}$ presented a theoretical intermittent flow model based on the works of ${ }^{13-16}$. However, the closure relationships employed for their study are based on empirical models developed for flow in circular pipes.

This study focuses on the measurement of slug flow parameters in horizontal annulus using electrical impedance probes (Conductance probes) developed for the study. These parameters would be employed as closure relationship for models to characterise intermittent flows in annular channels. The effect of annulus eccentricity on the measured slug flow parameters are studied as well as the performance of predictive models developed mainly for slug flow 
parameters in circular pipe when compared with experimental data. Most slug flow characterisation studies have been undertaken in circular pipes and as far back as the late 1960's and 1970's Gregory et al., ${ }^{17,18}$ measured slug frequency and slug liquid holdup in horizontal pipes with internal diameters of $0.019 \mathrm{~m}, 0.0258 \mathrm{~m}$ and $0.0512 \mathrm{~m}$ respectively. Carbon dioxide and water as well as air and light refined oil were used as the test fluids. A capacitance type volume fraction sensor was employed for slug flow parameters measurements. They developed empirical correlations for slug frequency and slug body holdup.

Experimental investigations were performed by Bendiksen ${ }^{19,20}$ to study the propagation of air bubbles in slug flow in pipes, with diameters of $0.019 \mathrm{~m}$ and $0.05 \mathrm{~m}$ respectively. Inclination angles ranged from $-30^{\circ}$ to $90^{\circ}$. Based on their experimental investigations, they suggested a correlation of bubble and average liquid velocities based on least squares data fit.

Later Andreussi \& Bendiksen ${ }^{20}$ determined the slug holdup for air-water flow in horizontal and near horizontal pipes using conductance probes. Experiments were conducted on a test section containing two transparent Plexiglas tubes with internal diameters of $0.05 \mathrm{~m}$ and 0.09 $m$ respectively. They developed semi-empirical models for prediction of slug holdup which captured the effects of inclination, fluid properties and pipe diameter on this parameter.

Similarly, Fossa et al., ${ }^{21}$, Wang et al., ${ }^{22}$ and Fan $\&$ Yan ${ }^{1}$ all employed conductance probes for measurement of slug flow parameters in horizontal circular pipes. For their part, Fossa et al., ${ }^{21}$ measured slug frequency, slug translational velocity, slug holdup and slug length. While Wang et al., ${ }^{22}$ on the other hand focused on slug length measurements using a single sensor conductance probe mounted at two different positions on the test section. Finally, Fan and Yan ${ }^{1}$ extracted physical characteristic parameters such as slug holdup, slug length and slug translational velocity using two conductance probe.

Al-Safran ${ }^{23,24}$ conducted studies to investigate slug frequency in horizontal pipes and developed new slug frequency correlations using a broad range experimental database. All the 
studies highlighted above were undertaken for flow through circular pipes and based on available literature, few studies have been published for slug flow characterisation in horizontal annuli.

\section{Experimental}

\section{Experimental Setup}

The experiments for this study were carried out in the Process Systems Engineering laboratory of Cranfield University. The experimental flow loop is as presented in Fig. 1(a). Air and water were the testing fluids with the air supplied to the flow loop using a screw compressor by AtlasCopco ${ }^{\circledR}$ model GA55 with a maximum discharge pressure of $7.5 \mathrm{barg}$ and free air maximum delivery capacity of $638 \mathrm{~m}^{3} / \mathrm{hr}$. Two automated valves (namely VC301 \& VC302) are used in regulating the air flow rate while measurement is undertaken by one of two Rosemount Mass Probar flow meters (FT302 and FT305) with accuracy of $\pm 1.4 \%$. Air flow rates ranging between $0-150 \mathrm{Sm}^{3} / \mathrm{hr}$ are measured by FT302 while flow rates above $150 \mathrm{Sm}^{3} / \mathrm{hr}$ are measured by FT305. Water flow to the flow loop is provided from a water tank with a capacity of $2 \mathrm{~m}^{3}$ using a progressive cavity pump with maximum discharge pressure of 6 barg. The water flow is measured using an Endress \& Hauser Promag 50 electromagnetic flow meter ranging between $0-18 \mathrm{~m}^{3} / \mathrm{hr}$, having an accuracy of $\pm 0.5 \%$. A stainless steel section of the flow loop with length of $2 \mathrm{~m}$, preceded the annulus test section and allowed for mixing of the phases before it entered the annulus section. A $2 \mathrm{~m}$ development length was allowed in the annulus test section before any instruments are placed. The fluid mixture exiting the annulus section enters a circular pipe section before being emptied into the water tank where gas-liquid separation takes place at atmospheric conditions.

A $60 \mathrm{~mm}$ x $76.8 \mathrm{~mm}$ annulus formed using two Polyvinyl Chloride (PVC) pipes having a test section length of $10.8 \mathrm{~m}$ is used to conduct tests. The flow observation and measurement sections are placed $6.01 \mathrm{~m}$ away from the point where the fluid mixture enters the annulus 
section (357 pipe diameters). Two static pressure transducers by GE Druck (model PMP 1400) and one by Wika (model A-10) ranging between 0-6 barg and having an accuracy of $\pm 0.25 \%$ of full scale are used to measure the static pressure in the test section. The mixture temperature of the fluids is measured by a J-type thermocouple with accuracy of $\pm 2.5^{\circ} \mathrm{C}$. In order to adjust the annulus eccentricity, an eccentricity adjuster is designed and fabricated from PVC rods with $4 \mathrm{~mm}$ pins fed through them. The pins are moved in or out to shift the inner pipe up or down depending on the desired annulus eccentricity. The pins are small enough to ensure that they don't interfere with the two-phase flow that goes through them (see Fig 1b).

Two pairs of ring-type electrical impedance probes were designed based on the recommendation of Fossa ${ }^{25}$ and flush mounted on a $430 \mathrm{~mm}$ length of perspex glass which formed part of the annulus test section and also served as the section for visual observation. The aspect ratio for the probe design was De/D $=0.34$, where De is the spacing between the electrodes and $\mathrm{D}$ is the annulus outer pipe diameter, resulting in electrode spacing of $26 \mathrm{~mm}$. Two electrode pairs were used each having a width of $6 \mathrm{~mm}$ and separated by a distance of 270 $\mathrm{mm}$ between each electrode pair. An electronic circuit is used to measure the electrical impedance between the electrodes with carrier frequency of $5 \mathrm{kHz}$ and $13 \mathrm{kHz}$ for the first and second pairs of conductance probes respectively. These probes are used for slug flow characterisation. Data is acquired from the experimental setup using a dedicated PC-based LabView ${ }^{\circledR}$ Data Acquisition System (DAS) consisting of National Instruments (NI) connector board interface and connected to the instrumentation using coaxial cables. Two-phase flow regimes images are captured using an OLYMPUS model i-SPEED 3 High speed camera at 1000 frames per second with lighting provided using Arrilite 800-W lights

\section{Experimental Procedure}

\section{Conductance Probes}


According to Fossa et al., ${ }^{21}$ a continuous measurement of the liquid height is provided by conductance probes and could be utilized to measure slug flow characteristics with some statistical analysis. They stated that based on experimental and analytical studies, the response of the conductance probe is a function of its geometry and the particular flow regime and as such, the average void fraction and mixture impedance changes with change in the phase distribution. To overcome this problem, the geometry of the conductance probes were chosen such they provide a response that it is insensitive to the changes that would occur with changes in flow regimes.

The aspect ratio (De/D) and width to diameter ratios $\left(\mathrm{S}_{\mathrm{P}} / \mathrm{D}\right)$ chosen for the probes employed in this study are (0.34) and (0.078) respectively which are in the range suggested by Devia \& Fossa., ${ }^{26}$. The arrangement of the conductance probes is as depicted in Figure 1(c).

To measure the fraction of the two phases under slug flow conditions with conductance probes, it is assumed that the slug flow regime is made up of stratified flow regions which are separated by liquid regions which may have some gas bubbles dispersed in them. In the annulus setup studied, the illustration of these regions is presented in Figure 1(d).

\section{Calibration of Conductance Probes}

The conductance probes were calibrated to characterise two pairs of ring probes to measure the liquid film height during intermittent flow. To achieve this, the electrode pairs were connected to a conductivity Electronic Box which supplies $5 \mathrm{kHz}$ and $13 \mathrm{kHz}$ alternating current (a.c.) carrier signal to probes a and $\mathrm{b}$ respectively. An offline calibration technique based on the recommendation of Fan $\&$ Yan $^{1}$ is carried out. It involves simulating the distribution of the gas-liquid phase by introducing known volumes of liquid into horizontally positioned concentric and fully eccentric annuli test conduits. Tap water was used and the tests were performed to cover liquid fractions between $0 \sim 1$. At each measurement point, the 
corresponding impedance value was recorded, where a high level voltage output of $5 \mathrm{~V}$ was obtained when the annulus section was filled completely with water and a low level voltage value of $0 \mathrm{~V}$ was obtained when the annulus was empty (filled with air). The voltage output from each pair of conductance probe was normalized using the maximum voltage value when the annulus was filled with water for each annulus setup, thus producing a dimensionless conductance value. A non-linear relationship was obtained between the liquid holdup and the dimensionless conductance; therefore calibration curves were generated for each probe pair and annulus setup. The relationship between the dimensionless conductance and liquid holdup was seen to increase with increased liquid holdup in the annulus conduit while a decrease was observed as gas fraction increased. The uncertainty of the conductance probes were found to be within $\pm 2 \%$ of indirect measurements. This could be much higher due to difference in actual flow conditions. However, the uncertainty would be within the $\pm 10 \%$ range because the liquid holdup is averaged.

\section{Experimental Scheme}

For this study, slug flow characteristics have been measured in two annulus eccentricity positions (i) concentric and (ii) fully eccentric. The annulus section eccentricity is adjusted appropriately using the $4 \mathrm{~mm}$ stainless steel pins described earlier. Before each experimental program commences, offset values of the flow meters and pressure transducers are determined from an empty test rig. The flow rate of the liquid phase is established using the pump control system consisting of manual valves, a variable speed controller and water flow meter. The flow rate of air at given values (in $\mathrm{Sm}^{3} / \mathrm{hr}$ ) is injected into the flow loop using the Emerson DeltaV PID controller implemented in the air supply section. Flow is allowed to stabilize for five minutes before data is logged for a duration of 180 seconds for each flow condition at a sampling frequency of $100 \mathrm{~Hz}$. The range of gas and liquid superficial velocities for slug flow characterisation were $0.45-3.49 \mathrm{~m} / \mathrm{s}$ and $0.15-2.77 \mathrm{~m} / \mathrm{s}$ respectively. During each test run, 
the standard volumetric rate of air is kept constant while the liquid flowrate is increased at an interval of $0.0005 \mathrm{~m}^{3} / \mathrm{s}$. This trend was repeated until the entire range of flowrates was covered. Visual observation and high speed camera recordings were made for each flow condition and all experimental runs were carried out at atmospheric pressure.

\section{Results \& Discussion}

\section{Slug Zone Classification in Horizontal Annulus}

Figure 1(d) gives an illustration of the slug flow zones adopted for this study. These zones give an idea as to where the non-intrusive conductance probes can continue to function. Slug flow can be defined as a liquid mass which travels through a conduit, driven by the difference in the dynamic pressure between the gas phase in front of and behind it, with the liquid mass blocking off the entire conduit ${ }^{27}$. The slug zones in Figure. 1(d) are labelled as A, B, C and D. The slug front is seen in zones (A-B), the slug liquid body is as depicted in zones (B-C) and the slug tail is seen in zones (C-D). Also, the arrangement of the probes is incorporated in this figure such that Do is the outer pipe diameter, Di is the inner pipe diameter, De is the spacing between the each probe pairs which is $270 \mathrm{~mm}$ and $\mathrm{S}_{\mathrm{P}}$ is electrode width $(6 \mathrm{~mm})$.

Statistical analysis is applied to the instantaneous liquid holdup time series obtained from the conductance probes to characterise slug flow in horizontal annuli. Parameters such as slug frequency, slug translational velocity, slug body and film lengths, and slug body holdup are measured. To accurately distinguish between the fully developed slugs and passing waves, researchers including Nydal et al. ${ }^{28}$, Fossa et al., ${ }^{21}$, Al-Lababidi ${ }^{27}$ and Fan \& Yan $^{1}$ suggest establishing a threshold value. Suggested threshold values ranged from $0.42-0.8$. For this study, the threshold value adopted is 0.7 and corresponds with values adopted by. Fossa et al., ${ }^{21}$ ' and Al-lababidi ${ }^{27}$. The instantaneous liquid holdup time series and threshold analysis is as presented in Figure 2(a). 


\section{Slug Frequency Measurements}

Slug frequency is an important parameter during the design of slug catchers and separators; it is a necessary input into mechanistic slug flow models used in predicting characteristics such as pressure drop and liquid holdup in pipelines ${ }^{24}$. The number of slugs passing through a specific point (in this case the conductance probes) in a conduit over a certain time period is called the slug frequency.

Al-Lababidi ${ }^{27}$ practically determined the slug frequency for his study by counting the number of slugs observed above the established threshold value of the liquid holdup and this approach is adopted here.

\section{Slug Frequency in Horizontal Concentric Annulus}

During air-water experiments conducted in the horizontal concentric annulus, conductance data is obtained for each test condition covering the range of gas and liquid superficial velocities investigated for slug flow. The liquid holdup is determined as a function of the dimensionless conductance of the probes used for the study. A slug trace for the conductance probes is drawn as shown in Figure 2(a), and a slug body peak count is conducted for signals with threshold value of above 0.7. A 30 seconds duration is used for each test point and visual analysis of high speed camera recordings is also done by counting the slugs passing through the test section viewing window over time.

Figure 3(a) shows the plot of slug frequency as a function of gas superficial velocity at different liquid superficial velocities in an horizontal concentric annulus. There is a weak dependence of the slug frequency on the gas superficial velocity. This is similar to results obtained by Wang et al., ${ }^{29}$ during their study in circular pipes.

On the other hand, the slug frequency is observed to increase with increase in liquid superficial velocity, showing a strong dependence on the liquid superficial velocity. 
The performance evaluation of the experimental slug frequency is carried out using correlations in literature ${ }^{17,21,24,29}$. The approach involves validating the slug frequency based on modified Strouhal number given as:

$$
S t=\frac{v * D_{H}}{V_{S G}}
$$

Where $v$ is frequency, $D_{H}$ is annulus hydraulic diameter defined as (Do-Di) and $V_{S G}$ is gas superficial velocity. The slug frequency data in terms of Strouhal number is plotted against the liquid volume fraction given by:

$$
X_{L}=\frac{V_{S L}}{V_{M}}
$$

$V_{S L}$ and $V_{M}$ are the liquid and mixture superficial velocities respectively. Fossa et al., ${ }^{21}$ developed from their empirical studies in two different circular pipes with internal diameters of $0.06 \mathrm{~m}$ and $0.04 \mathrm{~m}$ an empirical correlation for Strouhal number as follows:

$$
S t_{(\text {Fossa })}=\frac{v * D}{V_{S G}}=\frac{A * X_{L}}{1+B * X_{L}+C *\left(X_{L}\right)^{2}}
$$

The constants of the correlation (A, B and C) were inferred from slug frequency measurements and given as $\mathrm{A}=0.044, \mathrm{~B}=-1.71$ and $\mathrm{C}=0.70$.

Wang et al., ${ }^{29}$ also developed correlations based on Strouhal number for their slug frequency data similar to the empirical correlation of Fossa et al., ${ }^{21}$ but with different constants as follows:

$$
S t_{(\text {Wang })}=\frac{v * D}{V_{S G}}=\frac{0.05 X_{L}}{1-1.675 X_{L}+0.768\left(X_{L}\right)^{2}}
$$

Correlations used to validate the slug frequency values measured by conductance probes are presented in terms of Strouhal number in Table 1. 
Figure 3(b) shows the comparison of the Strouhal number obtained for the studies in an horizontal concentric annulus with those obtained from the correlations and the following can be inferred

- Slug frequency expressed as Strouhal number for two-phase flow in horizontal concentric annulus exhibits a similar trend as those obtained using the correlations explored.

- The correlation by Gregory \& $\operatorname{Scott}^{17}$ is the best performing matching the data of this study accurately up to liquid volumetric fraction of 0.56 . Above this liquid fraction, the correlation underestimates the slug frequency.

- The correlation of Al Safran ${ }^{24}$ over estimates the experimental data marginally.

- The correlations of Fossa and Coworkers ${ }^{21,29}$ significantly over estimate the Strouhal number values of the experimental data. This is probably because their constants were developed based on the experimental data from their studies.

\section{Effect of Annulus Eccentricity of slug Frequency}

To understand the effect of annulus eccentricity on slug frequency, experiments were conducted in a fully eccentric annulus. The experimental procedure was the same used for the concentric annulus. Similarly, there is no dependence of slug frequency on gas superficial velocity but rather on the liquid superficial velocity as observed in the concentric annulus. Figure 3(c) shows the comparison between the slug frequency in concentric and fully eccentric annuli. It is seen that at lower liquid superficial velocities, slug frequency is higher in the fully eccentric annulus than the concentric one. However, at higher liquid superficial velocities, higher slug frequencies are observed in the concentric annulus than for the fully eccentric one. A comparison of the slug frequency data obtained in the fully eccentric annulus with the correlations listed in Table 1 provides a similar trend as was observed in the concentric annulus and is shown in Figure 3(d). The correlation of Gregory \& Scott ${ }^{17}$ gives the best performance when compared with experimental frequency data up to the liquid volume fraction of 0.72 . Al- 
Safran ${ }^{24}$ correlation performs better with data obtained in the fully eccentric annulus when compared with that of the concentric annulus.

\section{Slug Translational Velocity Measurements}

The slug translational velocity for this study is determined by obtaining the time delay between two conductance probe signals using cross-correlation. The conductance probes are installed on the test section with a known spacing between the electrode pair $\mathrm{L}=0.308 \mathrm{~m}$ and the conductance signals from both pairs of probes were cross-correlated based on the following equation:

$$
R_{x y}=\frac{1}{T} \int_{0}^{T} x(t-\tau) y(t) d t
$$

Where $R_{x y}$ is cross-correlation function, $T$ is the extraction duration, $x(t-\tau)$ and $y(t)$ are the two conductance probe signals at time $(t-\tau)$ and $(t)$ respectively. The slug translational velocity is obtained as follows:

$$
V_{T}=\frac{L}{\tau}
$$

Where the separated distance between the conductance probes is $L$ and $\tau$ is the time delay obtained by cross-correlation technique. In order to cross-correlate the upstream and downstream conductance signals using the "xcorrel" subroutine of the MATLAB programming software version 2016a, the conductance signals must be extracted as shown in Figure 2(b) for slug flow in horizontal concentric annulus.

\section{Slug Translational Velocity in Concentric Annulus}

A plot of slug translational velocity as a function of gas superficial velocity at different liquid superficial velocities is as presented in Figure 4(a). The slug translational velocity is observed 
to increase with increases in gas and liquid superficial velocities' this is similar to what was reported ${ }^{27}$ for slug translational velocity in circular pipes.

\section{Slug Translational Velocity in an Eccentric Annulus}

The cross-correlation technique highlighted for slug translational velocity measurements is employed on conductance signals for the fully eccentric annulus. The slug flow conductance probe signals are as extracted in Figure 2(c). Similarly, the slug translational velocity increases with increase in gas and liquid superficial velocities as indicated on Figure 4(b).

The annulus eccentricity is observed to have little or no effect on the slug translational velocity observed in horizontal annuli.

\section{Extraction of Distribution Parameter and Drift Velocity}

Several researchers including Bendiksen ${ }^{19}$ reported that slug translational velocity is strongly related to the mixture velocity of the flow in the conduit. Nicklin et al., ${ }^{30}$ as cited in Wang et al., $^{22}$, Nicholson \& Gregory ${ }^{14}$ as well as Bendiksen ${ }^{19}$ all suggested that a linear relationship exists between the slug translational velocity, the mixture velocity and the drift velocity, such that;

$$
V_{T}=C_{0} V_{M}+V_{d}
$$

Where $C_{0}$ is the distribution parameter which is related to the velocity profile of dispersed systems, $V_{M}$ is the mixture velocity and $V_{d}$ is the drift velocity. The coefficient $C_{0}$ and $V_{d}$ can be expressed to be functions of the general expression:

$$
C_{0}=C_{0}\left(F r_{M}, R e_{S}, \sigma, \varphi\right)
$$




$$
V_{d}=V_{d}\left(F r_{M}, \operatorname{Re}_{S}, \sigma, \varphi\right)
$$

Where $F r_{M}$, is mixture Froude number defined by:

$$
F r_{M}=\frac{V_{M}}{\sqrt{g D_{H}}}
$$

And $R e_{S}$ is the slug Reynolds number given as follows:

$$
R e_{S}=\frac{\rho_{L} V_{M} D_{H}}{\mu_{L}}
$$

A correlation for the motion of the elongated gas bubble in an horizontal concentric annulus based on linear fit to experimental data is extracted for this study. The slug translational velocity measured using conductance probes is plotted against mixture velocity as shown in Figure 4(c).

An increase in mixture velocity results in a corresponding increase in slug translational velocity up to $3.85 \mathrm{~m} / \mathrm{s}$. Above this slug translational velocity, an increase in mixture velocity doesn't produce a corresponding increase in slug translational velocity.

Following the approach of ${ }^{19,27}$, the slug translational velocities versus mixture Froude number for mixture velocities is plotted in order to derive the coefficients $C_{0}$ and $V_{d}$. Two data groups are distinguished in this study based on the mixture Froude numbers; (i) Group 1 $\left(F r_{M} \leq 3.5\right)$ and (ii) Group $2\left(F r_{M} \geq 3.5\right)$ as shown in Figure 4(d). The coefficients $C_{0}$ and $V_{d}$ for each group is obtained based on a linear fit to the group data.

The plot of the slug translational velocity for each group as a function of mixture velocity and the following correlation can be defined for each group as follows as plotted on Figure 4(e):

$$
\text { Group 1: } \mathrm{V}_{\mathrm{T}}=1.4072 V_{M}+0.2767
$$




$$
\text { Group 2: } \mathrm{V}_{\mathrm{T}}=1.4643 V_{M}-0.2461
$$

The values of the distribution parameter $C_{0}$ and $V_{d}$ are given in Table 2 .

\section{Slug Body Length Measurements}

The slug body length is a requirement in most slug flow models and its prediction is quite difficult. It is strongly dependent on the pipe diameter although some issues have been raised when estimating slug length for smaller pipe diameters.

A statistical approach is adopted for the study of the slug body length distribution. The time of slug $\left(\mathrm{t}_{\text {slug }}\right)$ and film $\left(\mathrm{t}_{\text {film }}\right)$ are measured using the threshold analysis presented in Figure. 3. The width of the conductance probe signal when the slug body above the threshold values gives the time of slug while the time of film is the width of the probe signal when the film region is detected by the probe. The slug and film lengths are computed as follows:

$$
\begin{aligned}
& \mathrm{L}_{\mathrm{S}}=t_{\text {slug }} * \bar{V}_{T} \\
& \mathrm{~L}_{\mathrm{F}}=t_{\text {film }} * \bar{V}_{T}
\end{aligned}
$$

$\mathrm{L}_{\mathrm{S}}$ is the slug length, $t_{\text {slug }}$ is the slug body passing time, $L_{F}$ is the film region length, $t_{\text {film }}$ is the film region passing time and $\bar{V}_{T}$ is the averaged slug translational velocity measured using conductance probes.

\section{Slug Body Lengths in Concentric Annulus}

For the concentric annulus, the average slug body lengths are plotted as a function of gas superficial velocities at different liquid superficial velocities as shown in Figure 5(a). Slug lengths in concentric annulus are to a large extent independent of the gas superficial velocities. This was similarly reported ${ }^{27,28}$ for studies in circular pipes.

Different researchers reported constant slug lengths for a large range of mixture velocities during air-water flow in horizontal pipes. Dukler \& Hubbard ${ }^{13}$ and Andreussi \& Bendiksen ${ }^{20}$ 
reported slug lengths of $2 \mathrm{D}-24 \mathrm{D}$, Nicholson et al., ${ }^{24}$ and Al-Lababidi ${ }^{27}$ observed $\mathrm{L}_{\mathrm{S}}=12 \mathrm{D}$ - 30D, while Wang et al., ${ }^{15}$ reported two ranges of slug length which were 15D - 27D and 23D $-40 \mathrm{D}$, where the first range was obtained at a shorter measurement distance on their setup than the second one. On their part, Lage et al., ${ }^{12}$ used $30\left(\mathrm{D}_{\mathrm{H}}\right)$ as average slug length for the intermittent flow model for horizontal annulus as suggested by Nicholson et al., ${ }^{14}$. All these were reported for studies undertaken in horizontal circular pipes.

The range of slug length $L_{S}$ obtained during this study in concentric annulus was between $\left(13 \mathrm{D}_{\mathrm{H}}-72 \mathrm{D}_{\mathrm{H}}\right)$. The average slug length obtained using conductance probes in the horizontal concentric annulus is approximately $\left(37 \mathrm{D}_{\mathrm{H}}\right)$. It is higher than range of slug lengths reported in most literature for slug lengths in circular pipes. Also, it is higher than the value employed by Lage et al., ${ }^{12}$ for closure of their model. This would result in huge errors in their pressure drop estimates for intermittent flow. The geometry effect may be responsible for the difference observed, as in annulus channels gas/liquid phase separation is more difficult than that in circular channels.

\section{Effect of Annulus Eccentricity of Slug Body Length}

The slug body lengths measured in fully eccentric annulus are similarly independent of the gas and liquid superficial velocities. However, longer slug lengths are observed in the fully eccentric annulus when compared with those measured in the concentric one. Studies carried out by Mitsuishi \& Aoyagi ${ }^{31}$ who measured point velocities of non-Newtonian solutions in eccentric annuli and Haciilamoglu \& Langlinais ${ }^{32}$ who developed numerical models to compute the velocity profile in concentric and eccentric annuli show that velocities are reduced in the reduced section of the eccentric annulus and depend on the diameter ratios as well as the annulus eccentricity. It is envisaged that this reduction in the velocities at this point will affect the average velocity of the liquid phase which flows at the lower part of the annulus in the 
horizontal system. This would in turn affect the slippage in the fully eccentric annulus making it higher than in the concentric one.

Dimensionless slug length measured in the fully eccentric annulus ranged between $31 \mathrm{D}_{\mathrm{H}}-$ $111 \mathrm{D}_{\mathrm{H}}$ and a comparison between the dimensionless slug length in concentric and fully eccentric annulus setups are as presented in Figure 5(b). The lower and upper ranges of slug length are 2.4 and 1.5 times respectively those measured in the concentric annulus. This is quite significant considering the importance of this parameter in modelling of slug flow and design of equipment. Also, the average slug length observed in the fully eccentric annulus is $57 \mathrm{D}_{\mathrm{H}}$, significantly different from $37 \mathrm{D}_{\mathrm{H}}$, the slug length observed in the concentric annuli. The comparison presented in Figure 5(b) is based on the standard hydraulic diameter concept for both annulus setups defined as follows:

$$
D_{H}=D o-D i
$$

Where $D o$ is the inner diameter of the outer pipe and $D i$ is the outer diameter of the inner pipe. It is observed that a $35 \%$ difference in the average dimensionless slug lengths of both annulus setups is due to this diameter concept.

For this study, the largest gap of the annulus channels is considered as an appropriate definition of hydraulic diameter of the channel. For the concentric annulus, it is defined as:

$$
D_{H_{\text {largest gap }}}=\left(\frac{D o}{2}\right)-\left(\frac{D i}{2}\right)
$$

For the fully eccentric annulus, the largest gap of the channel is the difference of the outer and inner diameters, hence is identical to the conventional definition of the hydraulic diameter in such channels.

Using the new proposed largest gap hydraulic diameter concept and the experimental result, the dimensionless slug length is re-presented in Figure 5(c). It can be observed that the 
dimensionless slug lengths in the concentric and fully eccentric annulus setups have been brought closer together. The observed difference in the average slug lengths is reduced to about $23 \%$.

\section{Slug Body Holdup Measurements}

The slug body holdup for this study was measured using statistical analysis of the instantaneous liquid holdup time series obtained from conductance probes. The instantaneous liquid holdup values above the threshold value were averaged for each slug flow condition encountered.

In Figure 6(a), the measurement of the slug body holdup by conductance probe techniques at slug flow condition observed at $\left(\mathrm{V}_{\mathrm{SL}}=0.15 \mathrm{~m} / \mathrm{s}, \mathrm{V}_{\mathrm{SG}}=0.63 \mathrm{~m} / \mathrm{s}\right)$ in an horizontal concentric annulus. The slug body and film region traces can be seen as detected by the conductance probe, after threshold analysis has been applied to develop the fully developed slugs from the travelling waves. The measured slug holdup obtained in this study were compared with prominent predictive models developed for circular pipes available in literature. Gregory et al., ${ }^{18}$, Malnes ${ }^{33}$ as cited in Al-Lababidi ${ }^{27}$ and Paglianti et al., ${ }^{34}$ predictive models performances were evaluated.

These predictive models are as follows:

Gregory et al., ${ }^{18}$

$$
H_{L S}=\frac{1}{1+\left(\frac{V_{M}}{8.66}\right)^{1.39}}
$$

Malnes ${ }^{33}$

$$
H_{L S}=\frac{V_{M}}{C_{M}+V_{M}}, C_{M}=83\left(\frac{g \sigma}{\rho_{L}}\right)^{1 / 4}
$$

Paglianti et al., ${ }^{34}$ 


$$
H_{L S}=\frac{1}{\left(1+\frac{F r^{2} * B o^{0.2}}{625}\right)^{2}}
$$

Where Fr is the Froude number given as:

$$
F r=\frac{V_{M}}{\sqrt{g D_{H}}}
$$

And Bo is the Bond number defined as:

$$
B o=\frac{\Delta \rho * g * D_{H}^{2}}{\sigma}
$$

\section{Slug Holdup Measurements in Concentric Annulus}

The slug body holdup measured in the concentric annulus are plotted versus the gas superficial velocity at different liquid superficial velocities as shown in Figure 6(b). Generally, the slug holdup decreased with an increase in the gas superficial velocities. Also, a slight decrease is noticed with increase in liquid superficial velocities above $1.39 \mathrm{~m} / \mathrm{s}$.

The predictive models above were compared with the measured slug body holdup values obtained in the concentric annulus using the conductance probes and the results are as presented on Figure 6(c).

Statistical results of the performance of the predictive models with experimental data are shown in Table 3. It can be seen that the predictive model of Malnes ${ }^{33}$ performs best when compared with slug holdup data from concentric annulus although all the models tested have comparable results. The Gregory et al., ${ }^{18}$ model performs equally very well with the experimental data set but the Malnes ${ }^{33}$ model performed slightly better because it was based on modified representation of the former model. On the other hand, the model proposed by Paglianti et al.,

${ }^{34}$ has the worst statistical performance with absolute average percentage error (AAPE) OF $16.85 \%$ and a standard deviation of 14.6. It is worth noting however, that none of these 
predictive models were developed for flow in horizontal annuli but rather for flow through circular pipes and have been extended to the annulus geometry using the standard hydraulic diameter concept. The errors may be a result of the geometry effect which may not be adequately captured by the hydraulic diamter.

\section{Effect of Annulus Eccentricity on Slug Body Holdup}

The slug body holdup is measured in the fully eccentric annulus to study the effect of annulus eccentricity on slug body holdup. A similar trend is observed when the slug body holdup is plotted as a function of gas superficial velocity as observed in the concentric annulus. The slug body holdup is observed to decrease with increase in gas superficial velocity. At lower liquid superficial velocities, a slight decrease is noticed with increased liquid superficial velocity, however at $\mathrm{V}_{\mathrm{SL}}$ above $0.56 \mathrm{~m} / \mathrm{s}$, there's no effect of liquid superficial velocity increase on slug body holdup. Figure 7(a) shows the slug holdup as a function of gas superficial velocity in a fully eccentric annulus.

The effect of the annulus eccentricity on slug body holdup is presented in Figure7(c) by plotting the measured slug body holdup in both concentric and fully eccentric horizontal annuli as a function of the mixture Froude Number. Higher slug body holdup values are generally observed in the fully eccentric annulus when compared with the concentric one. The slippage effect already highlighted probably plays a role in the observed trend. Also, it is possible that the concentric annulus disrupts gas entrainment at the slug front.

Also, the experimental data obtained in the fully eccentric annulus for slug body holdup was compared with the same predictive models. The results are as presented in Figure 7(b) and it can be seen the predictive models of Gregory $\& \operatorname{Scott}^{18}$ as well as those by Malnes ${ }^{33}$ predict fairly accurately the experimental data. However, the statistical results obtained for the model comparison and presented on Table 4 shows that the Malnes ${ }^{33}$ model performs best, while the 
Paglianti et al ${ }^{34}$ performs badly when compared with the experimental data obtained in the fully eccentric annulus.

\section{Conclusion}

During this study, two-phase air-water experiments have been conducted in two annulus geometries; (i) concentric and (ii) fully eccentric annulus in order to characterise two-phase gas-liquid slug flow in an horizontal annulus. A $10.8 \mathrm{~m}$ long annulus section with outer diameter of $0.0768 \mathrm{~m}$ and inner diameter of $0.060 \mathrm{~m}$ was used and the gas and liquid superficial velocity ranges investigated during this study for slug flow characterisation were 0.45 $3.49 \mathrm{~m} / \mathrm{s}$ and $0.15-2.77$ respectively. Slug flow characteristics measured include slug frequency, slug translational velocity, slug length and slug body holdup and the following can be summarised from the results:

- For both geometries, he slug frequency is largely unaffected by the gas superficial velocity. However, an increase in liquid superficial velocity results in slug frequency increase. Also, the annulus eccentricity results in higher slug frequency in the fully eccentric annulus when compared with the concentric one.

- Annulus eccentricity is observed to have no effect on the slug translational velocity.

- The range of slug length observed in the concentric was $15 \mathrm{D}_{\mathrm{H}}-72 \mathrm{D}_{\mathrm{H}}$ with average length of $37 \mathrm{D}_{\mathrm{H}}$. On the other hand, the fully eccentric annulus had slug length ranges between $31 D_{H}-111 D_{H}$ with average length of $57 D_{H}$. Annulus eccentricity appears to cause the average slug length to be increased 1.5 times with observed difference in slug length of $33 \%$.

- A new hydraulic diameter concept based on the largest channel gap is incorporated to reduce the observed difference in the dimensionless slug length between both annulus geometries. 
- Slug body holdup data obtained in both concentric and fully eccentric annulus indicates that the annulus eccentricity affects the slug body holdup determined in horizontal annuli This study has provided closure relationships for intermittent flow models developed for flow through horizontal annuli that would eliminate errors which would result from using correlations developed for flow through circular pipes. More studies are however needed to check the effect of scale, higher pressures, temperature as well as using different fluid properties on slug characteristics. The slug flow parameters measured will be suitable for equipment design engineers to design slug catchers, separators and pipe lines for the oil and gas industry. Also, process control engineers can find useful information for implementing slug control measures which may become necessary at certain conditions due to overall economics of the process.

\section{Acknowledgment}

Edem Nsefik Eyo wishes to acknowledge The Petroleum Technology Development Fund of Nigeria (PTDF) for funding this research

\section{Notation}

$\begin{array}{cl}\text { Do } & \text { Inner diameter of outer pipe (m) } \\ \text { Di } & \text { Outer diameter of inner pipe (m) } \\ \mathbf{D}_{\boldsymbol{H}} & \text { Hydraulic diameter of annulus (m) } \\ \boldsymbol{F r}_{\boldsymbol{M}} & \text { Mixture Froude number(-) } \\ \mathbf{C}_{\boldsymbol{0}} & \text { Distribution Parameter (-) } \\ \mathbf{H}_{L S} & \text { Slug body holdup (-) }\end{array}$




$\begin{array}{ll}\mathbf{V}_{\boldsymbol{T}} & \text { Slug translational velocity }(\mathrm{m} / \mathrm{s}) \\ \boldsymbol{X}_{\boldsymbol{L}} & \text { Liquid volume fraction (-) } \\ \boldsymbol{S t} & \text { Strouhal number (-) } \\ \boldsymbol{B \boldsymbol { r }} & \text { Bond number } \\ \boldsymbol{\mu}_{\boldsymbol{L}} & \text { Liquid viscosity (cP) } \\ \boldsymbol{v} & \text { Slug Frequency (Hz) } \\ \boldsymbol{\rho}_{\boldsymbol{L}} & \text { Density of liquid phase }\left(\mathrm{kg} / \mathrm{m}^{3}\right) \\ \boldsymbol{g} & \text { Acceleration gravity }\left(\mathrm{m} / \mathrm{s}^{2}\right)\end{array}$

\section{Literature Cited}

1. Fan S, Yan T. Two-phase air-water slug flow measurement in horizontal pipe using conductance probes and neural network. IEEE Trans Instrum Meas. 2014;63(2):456466. doi:10.1109/TIM.2013.2280485

2. Salcudean M, Chun JH, Groeneveld D. Effect of flow obstruction on void distribution in horizontal air-water flow. Int J Multiph Flow. 1983;9(I):91-96.

3. Osamusali S., Chang J. Two phase flow regime transition in a horizontal pipe and annulus flow under gas-liquid two-phase flow. ASME Fundam Gas-Liquid Flows. 1988;FED-72:63-69.

4. Metin CO, Ozbayoglu M. Two-Phase Fluid Flow through Fully Eccentric Horizontal Annuli: A Mechanistic Approach. In: SPE/ICoTA Coiled Tubing and Well Intervention Conference and Exhibition. Texas; 2007:1-7.

5. Omurlu C, Ozbayoglu EM. A New Mechanistic Model For Two-Phase Flow Through Eccentric Horizontal Annulus. In: SPE Europe/EAGE Annual Conference and 
Exhibition. Vienna,Austria; 2006. doi:10.2523/100300-MS

6. Osgouei RE, Ozbayoglu EM. Flow Pattern Identification of Gas-Liquid Flow Through Horizontal Annular Geometries. In: SPE Oil and Gas India Conference and Exhibition. ; 2010:1-9.

7. Osgouei RE, Ozbayoglu ME, Ozbayoglu AM. A Mechanistic Model to Characterize the Two Phase Drilling Fluid Flow through Inclined Eccentric Annular Geometry. In: SPE Oil and Gas India Conference and Exhibition. Mumbai, India; 2012.

8. Osgouei RE, Ozbayoglu ME, Ozbayoglu M, Yuksel EH. The Determination of Two Phase Liquid-Gas Flow Behavior through Horizontal Eccentric Annular Geometry by Modification of Beggs \$ Brill and Lockhart \& Martinelli Models. In: Proceedings of the ASME 2013 Fluids Engineering Division Summer Meeting. Nevada: ASME; 2013:1-9.

9. Gschnaidtner T. Two-Phase Flow (Air-Water) Characteristics in Annulus. 2013;(September).

10. Nossen J, Liu L, Skjæraasen O, et al. An experimental study of two-phase flow in horizontal and inclined annuli. 2017:87-102.

11. Eyo EN, Lao L. Gas-liquid flow regimes in horizontal annulus. J Pet Sci Eng. 2019;175. doi:10.1016/j.petrol.2018.12.056

12. Lage ACVM, Rommetveit R, Time RW, College S. An Experimental and Theoretical Study of Two-Phase Flow in Horizontal or Slightly Deviated Fully Eccentric Annuli. 2000.

13. Dukler AE, Hubbard MG. A Model for Gas-Liquid Slug Flow in Horizontal and Near Horizontal Tubes. 1975;14(May):337-347. doi:10.1021/i160056a011

14. Nicholson MK, Gregory GA. Intermittent two-phase flow in horizontal pipes: predictive 
models. Can J Chem Eng. 1978;56:653-663.

15. Scott SL, Kouba GE, Spe. Advances in slug flow characterization for horizontal and slightly inclined pipelines. 65th Annu Tech Conf Exhib ot Soc Pet Eng. 1990:125-140. doi:10.2118/20628-MS

16. Taitel Y, Barnea D. A consistent Approach for Calculating Pressure Drop in Inclined Slug Flow. 1990;45(5):1199-1206.

17. Gregory GA, Scott D. Correlation of liquid slug velocity and frequency in horizontal cocurrent gas-liquid slug flow. AIChE J. 1969;15:933-935.

18. Gregory GA, Nicholson MK, Aziz K. Correlation of the liquid volume fraction in the slug for horizontal gas-liquid slug flow. Int J Multiph Flow. 1978;4(1):33-39. doi:10.1016/0301-9322(78)90023-X

19. Bendiksen K. An Experimental Investigation of the Motion Long Bubbles in Inclined Tubes. Int J Multiph Flow. 1984;10(4):467-483.

20. Andreussi P, Bendiksen K. An Investigation of Void Fraction in Liquid Slugs for Horizontal and Inclined Gas-Liquid Pipe Flow. Int J Multiph Flow. 1989;15(6):937-946.

21. Fossa M, Guglielmini G, Marchitto A. Intermittent flow parameters from void fraction analysis. Flow Meas Instrum. 2003;14(4-5):161-168. doi:10.1016/S09555986(03)00021-9

22. Wang X, Guo L, Zhang X. Development of Liquid Slug Length in Gas-Liquid Slug Flow along Horizontal Pipeline: Experiment and Simulation. Chinese J Chem Eng. 2006;14(5):626-633. doi:10.1016/S1004-9541(06)60125-0

23. Al-Safran E. Investigation and prediction of slug frequency in gas/liquid horizontal pipe flow. J Pet Sci Eng. 2009;69(1-2):143-155. doi:10.1016/j.petrol.2009.08.009 
24. Al-Safran EM. Probabilistic modeling of slug frequency in gas/liquid pipe flow using the Poisson probability theory. J Pet Sci Eng. 2016;138:88-96. doi:10.1016/j.petrol.2015.12.008

25. Fossa M. Design and performance of a conductance probe for measuring the liquid fraction in two-phase gas-liquid flows. Flow Meas Instrum. 1998;9(2):103-109. doi:10.1016/S0955-5986(98)00011-9

26. Devia F, Fossa M. Design and optimisation of impedance probes for void fraction measurements. Flow Meas Instrum. 2003;14(4-5):139-149. doi:10.1016/S09555986(03)00019-0

27. Al-Lababidi S. Multiphase Flow Measurement in the Slug Regime Using Ultrasonic Measurement Techniques and Slug Closure Model. 2006.

28. Nydal OJ, Pintus S, Andreussi P. Statistical Characterization of Slug Flow in Horizontal Pipes. Int J Multiph flow. 1992;18(3):439-453.

29. Wang X, Guo L, Zhang X. An experimental study of the statistical parameters of gasliquid two-phase slug flow in horizontal pipeline. Int J Heat Mass Transf. 2007;50(1112):2439-2443. doi:10.1016/j.ijheatmasstransfer.2006.12.011

30. Nicklin DJ, Wilkes M., Davidson J. Two-phase flow in vertical tubes. TransInstn Chem Engrs. 1962;40:61-68.

31. Mitsuishi N, Aoyagi Y. Non-Newtonian Fluid Flow in Eccentric Annulus. J Chem Eng Japan. 1973;6:402-408.

32. Haciislamoglu, M.Langlinais J. Non-Newtonian Flow in Eccentric Annuli. J Energy Resour Technol. 1990;112(September 1990):163-169.

33. Malnes D. Slip relations and momentum equation in two-phase flow. J Chem Eng 
Commun. 1979;141:71-102.

34. Paglianti A, Andreussi P, Nydal OJ. The effect of fluid properties and Geometries on Void Distribution in Slug Flow. 1993, in BHR Conference Cannes 6th International Conference on Multi Phase Production, Cannes, France, on 16-18 June 1993. 


\section{List of Figures Captions}

Figure 1. (a) Schematic of experimental setup; (b) Eccentricity adjuster; (c) Conductance probe arrangements; (d) Slug flow regions in horizontal concentric annulus.

Figure 2. (a) Threshold analysis on conductance probes; (b) Conductance probe signals Ca and $\mathrm{Cb}$ from concentric annulus $\left(\mathrm{V}_{\mathrm{SL}}=0.15 \mathrm{~m} / \mathrm{s}, \mathrm{V}_{\mathrm{SG}}=0.63 \mathrm{~m} / \mathrm{s}\right)$; (c) Conductance probe signals $\mathrm{Ca}$ and $\mathrm{Cb}$ from fully eccentric annulus $\left(\mathrm{V}_{\mathrm{SL}}=0.15 \mathrm{~m} / \mathrm{s}, \mathrm{V}_{\mathrm{SG}}=0.63 \mathrm{~m} / \mathrm{s}\right)$.

Figure 3. (a) Slug frequency in horizontal concentric annulus; (b) Strouhal number vs Liquid volumetric fraction in concentric annulus; (c) Effect of annulus eccentricity on slug frequency; (d) Strouhal number vs Liquid volumetric fraction in fully eccentric annulus.

Figure 4. (a) Slug velocity as a function of gas superficial velocity in horizontal concentric annulus; (b) Slug translational velocity vs gas superficial velocity in horizontal fully eccentric annulus; (c) Slug translational velocity as a function of mixture velocity for horizontal concentric annulus; (d) Slug translational velocity vs Mixture Froude Number in concentric annulus; (e) Extraction of linear coefficients $C_{0}$ and $V_{d}$ in an horizontal concentric annulus

Figure 5. (a) Slug body lengths as a function gas superficial velocity in concentric annulus; (b) Dimensionless mean slug length as a function of mixture velocity in horizontal annulus based on hydraulic diameter concept (Error bars represents the standard deviation from the mean value); (c) Dimensionless mean slug length as a function of mixture velocity in horizontal annulus based on largest gap diameter concept. (Error bars represent the standard deviation from the mean value). 
Figure 6. (a) Slug Holdup measurements at $\left(\mathrm{V}_{\mathrm{SL}}=0.15 \mathrm{~m} / \mathrm{s}, \mathrm{V}_{\mathrm{SG}}=0.63 \mathrm{~m} / \mathrm{s}\right)$; (b) Measured slug holdup as a function of gas superficial velocity in concentric annulus; (c) Comparison of slug body holdup from concentric annulus with predictive models.

Figure 7. (a) Measured slug body holdup vs gas superficial velocity in fully eccentric annulus;

(b) Comparison of slug body holdup from fully eccentric annulus with predictive models; (c) Effect of annulus eccentricity on slug body holdup. 


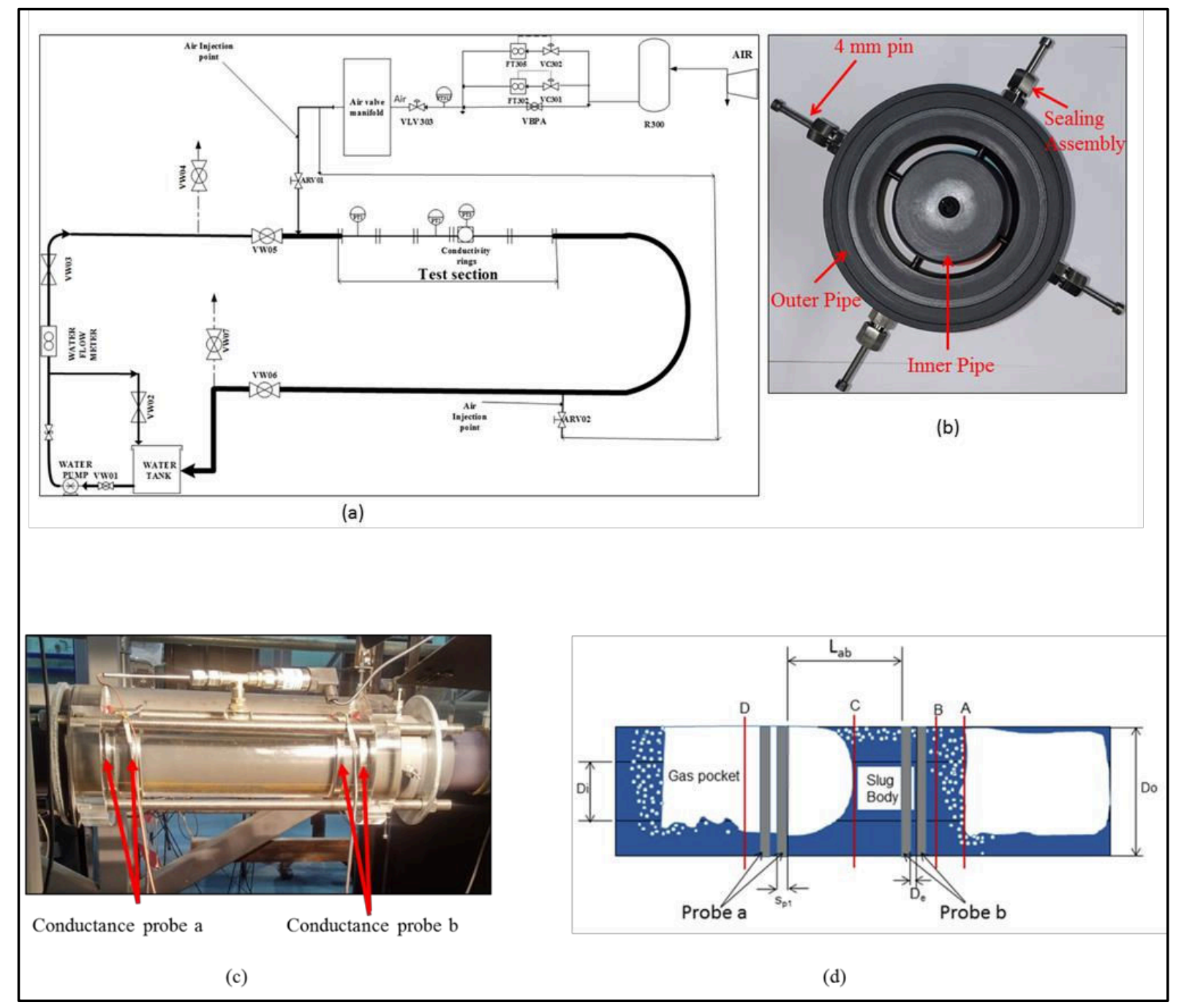

Figure 1: (a) Schematic of experimental setup; (b) Eccentricity adjuster; (c) Conductance probe arrangements; (d) Slug flow regions in horizontal concentric annulus. 


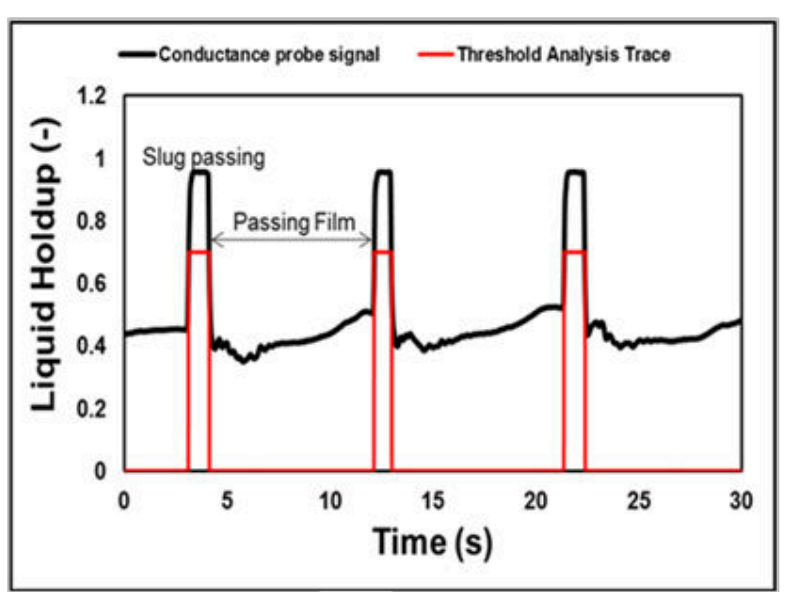

(a)

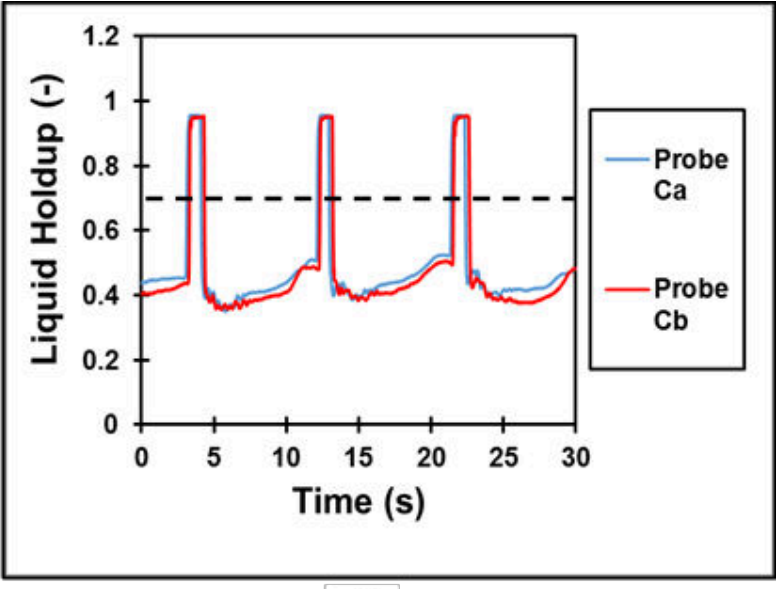

(b)

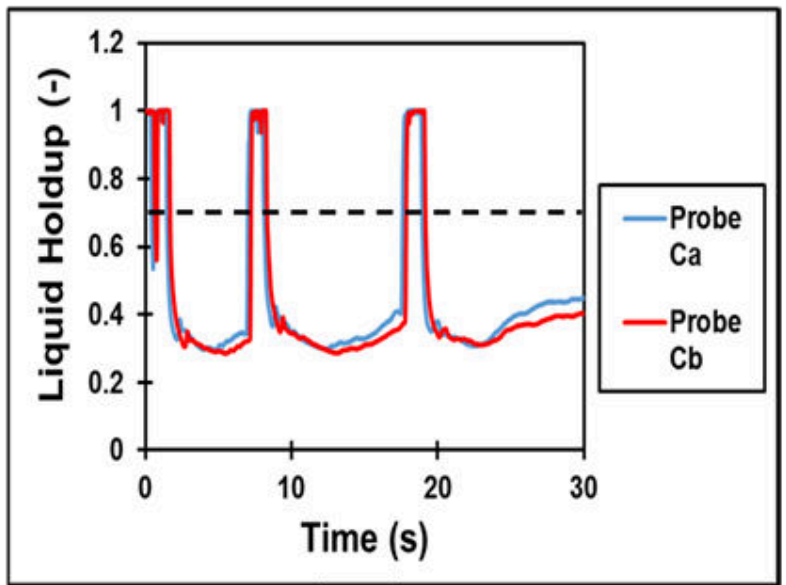

(c)

Figure 2: (a) Threshold analysis on conductance probes; (b) Conductance probe signals $\mathrm{Ca}$ and $\mathrm{Cb}$ from concentric annulus $\left(\mathrm{V}_{\mathrm{SL}}=0.15 \mathrm{~m} / \mathrm{s}, \mathrm{V}_{\mathrm{SG}}=0.63 \mathrm{~m} / \mathrm{s}\right)$; (c) Conductance probe signals $\mathrm{Ca}$ and $\mathrm{Cb}$ from fully eccentric annulus $\left(\mathrm{V}_{\mathrm{SL}}=0.15 \mathrm{~m} / \mathrm{s}, \mathrm{V}_{\mathrm{SG}}=0.63 \mathrm{~m} / \mathrm{s}\right)$. 


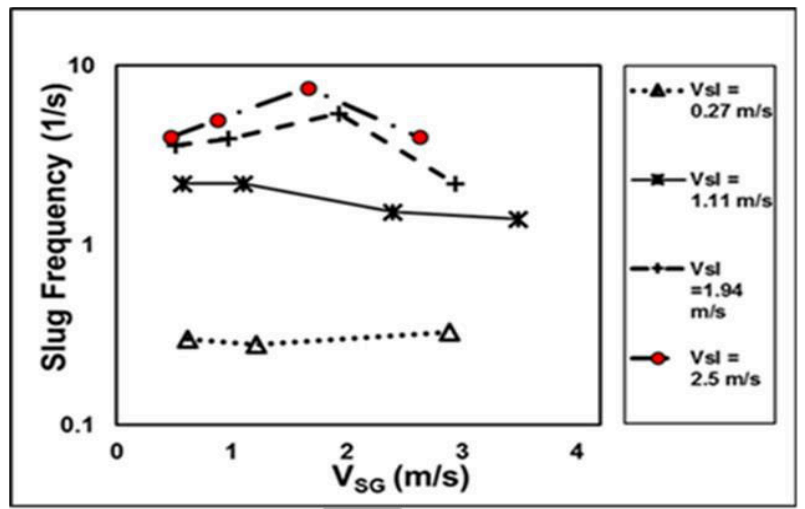

(a)

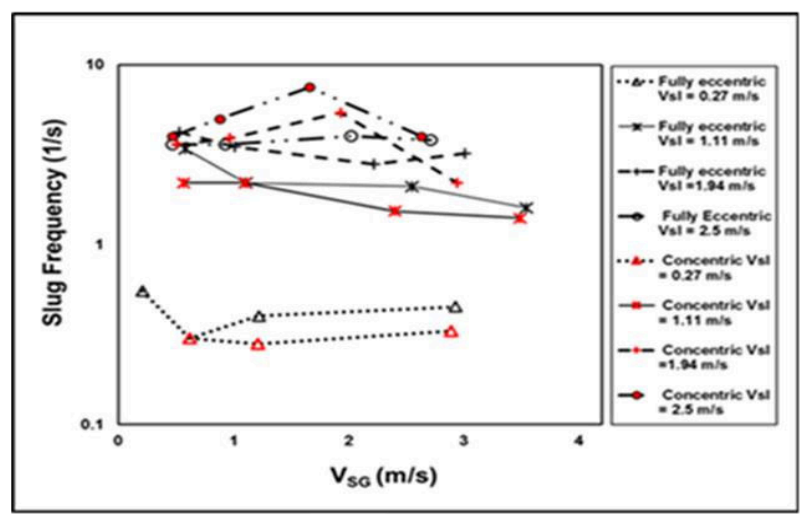

(c)

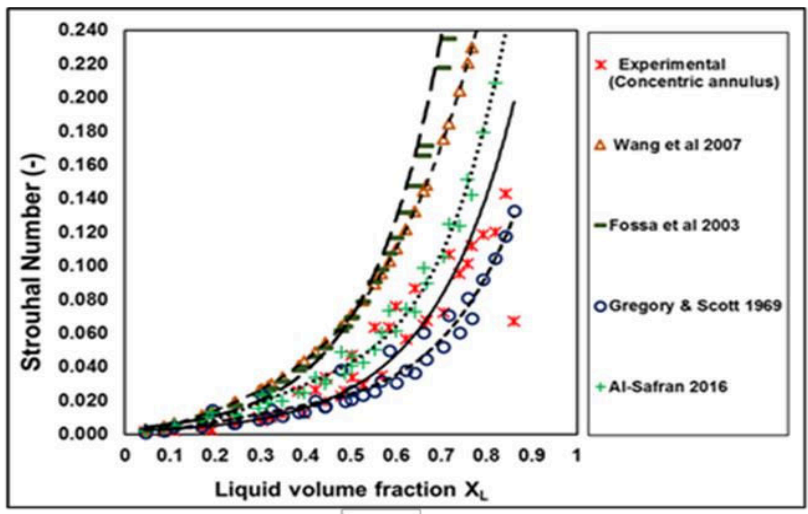

(b)

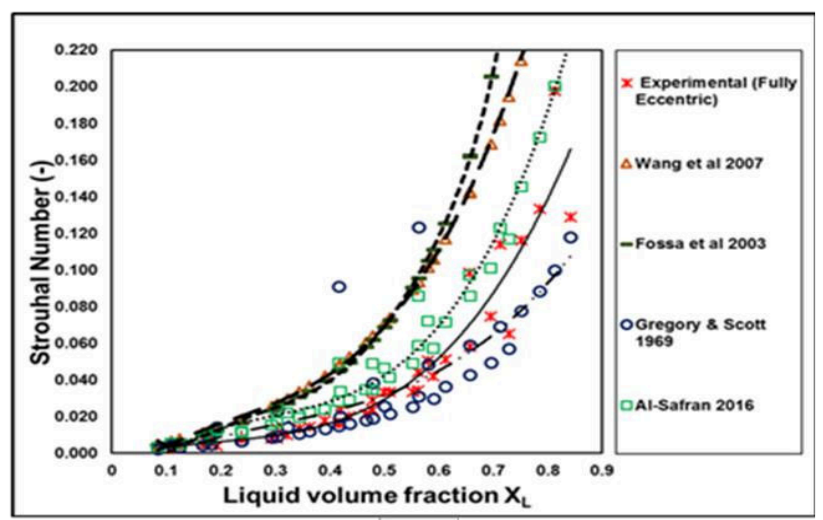

(d)

Figure 3: (a) Slug frequency as a function of gas superficial velocity in horizontal concentric annulus; (b) Strouhal number vs Liquid volumetric fraction in concentric annulus; (c) Effect of annulus eccentricity on slug frequency; (d) Strouhal number vs Liquid volumetric fraction in fully eccentric annulus. 


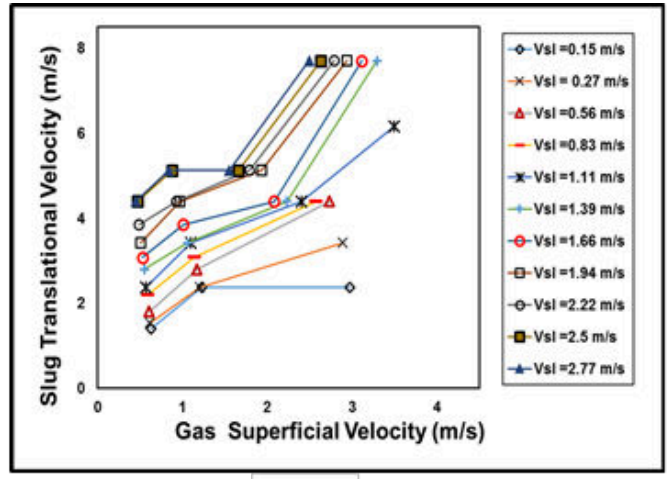

(a)

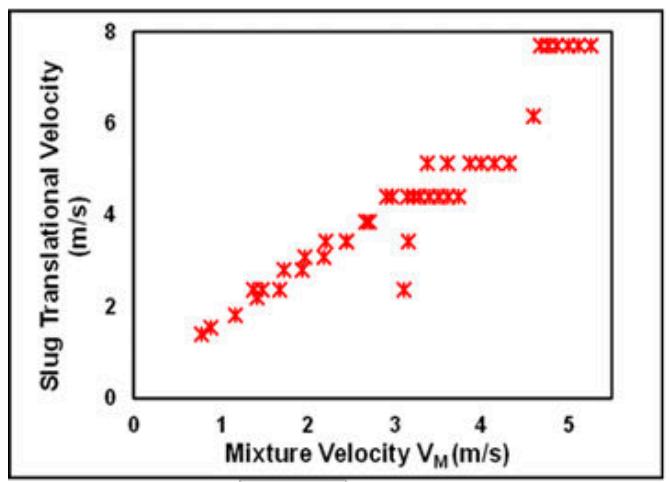

(c)

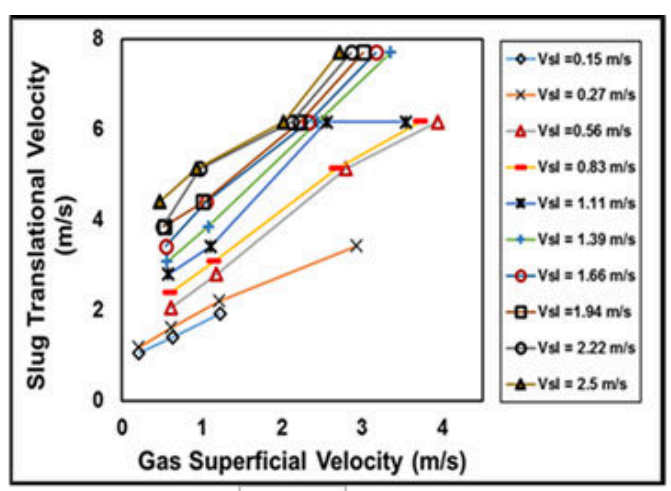

(b)

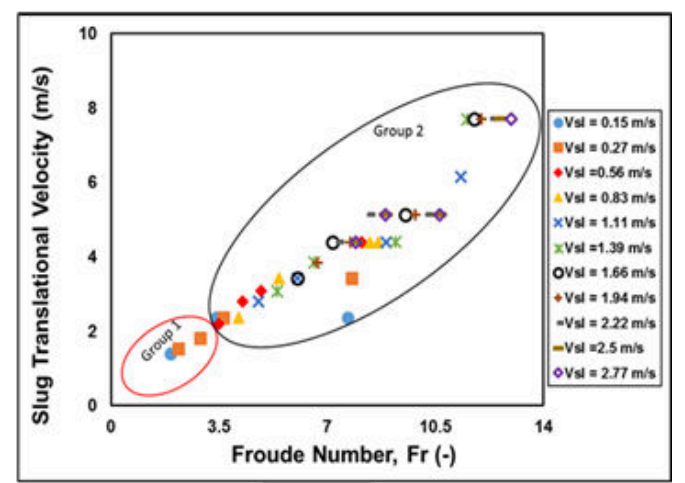

(d)

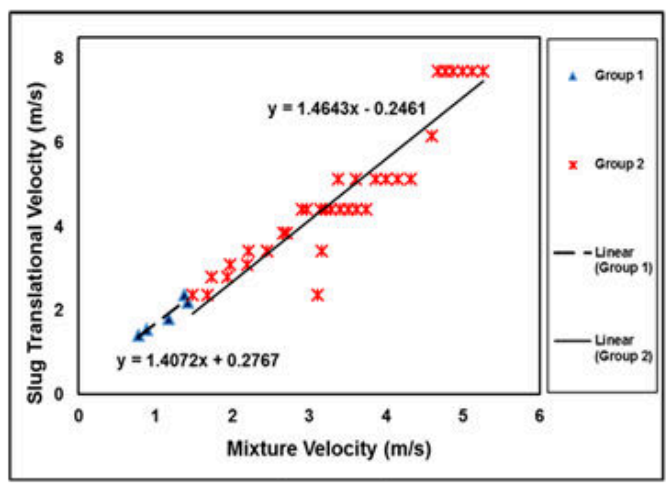

(e)

Figure 4: (a) Slug velocity as a function of gas superficial velocity in horizontal concentric annulus; (b) Slug translational velocity vs gas superficial velocity in horizontal fully eccentric annulus; (c) Slug translational velocity as a function of mixture velocity for horizontal concentric annulus; (d) Slug translational velocity vs Mixture Froude Number in concentric annulus; (e) Extraction of linear coefficients $C_{0}$ and $V_{d}$ in an horizontal concentric annulus. 


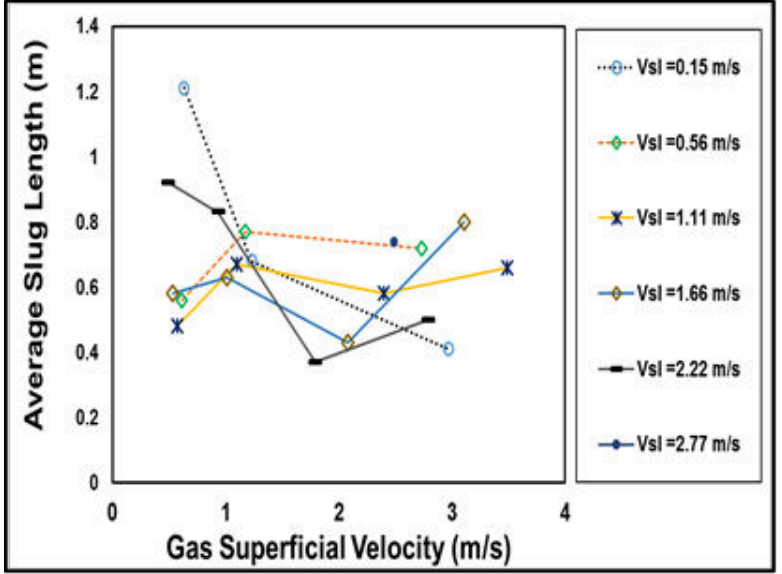

(a)

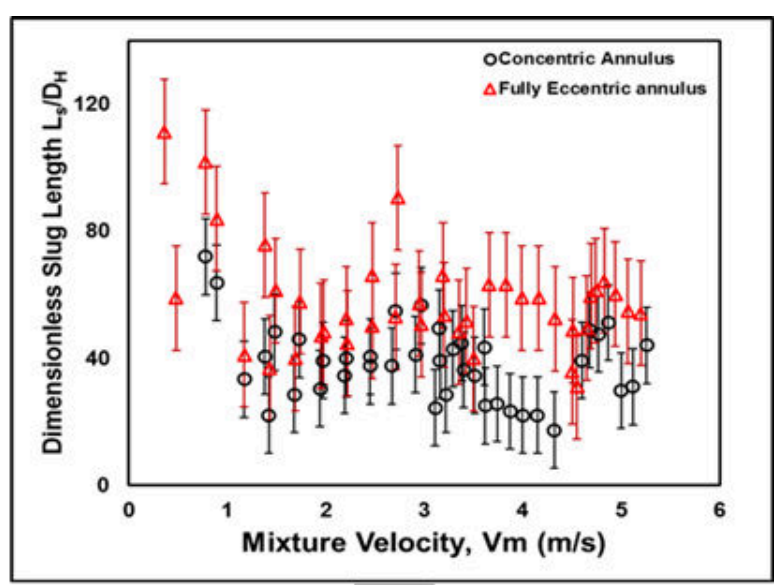

(b)

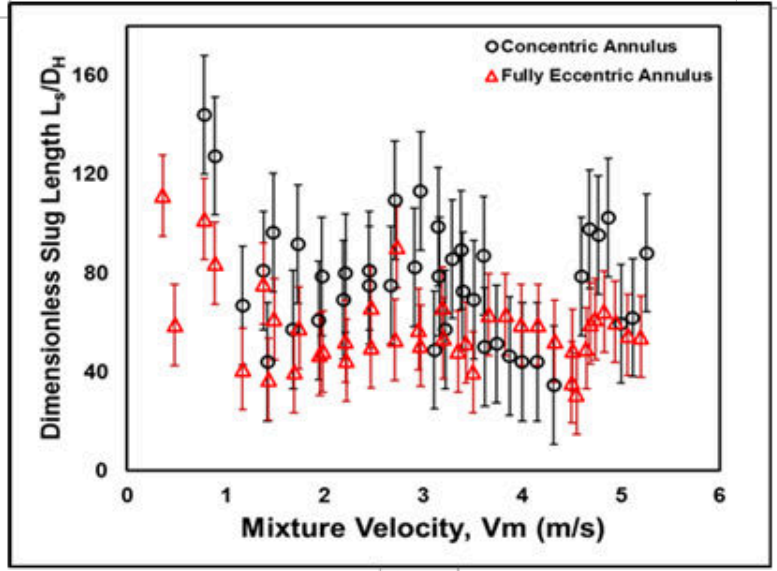

(c)

Figure 5: (a) Slug body lengths as a function gas superficial velocity in concentric annulus; (b) Dimensionless mean slug length as a function of mixture velocity in horizontal annulus based on hydraulic diameter concept (Error bars represents the standard deviation from the mean value); (c) Dimensionless mean slug length as a function of mixture velocity in horizontal annulus based on largest gap diameter concept. (Error bars represent the standard deviation from the mean value). 


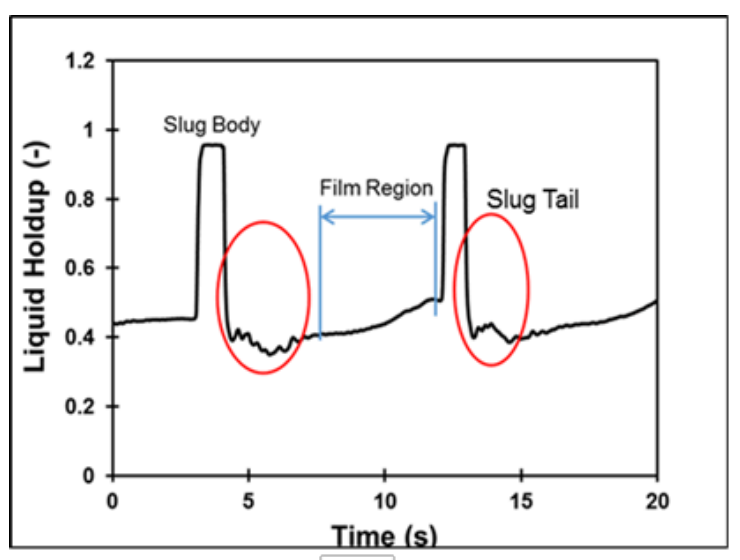

(a)

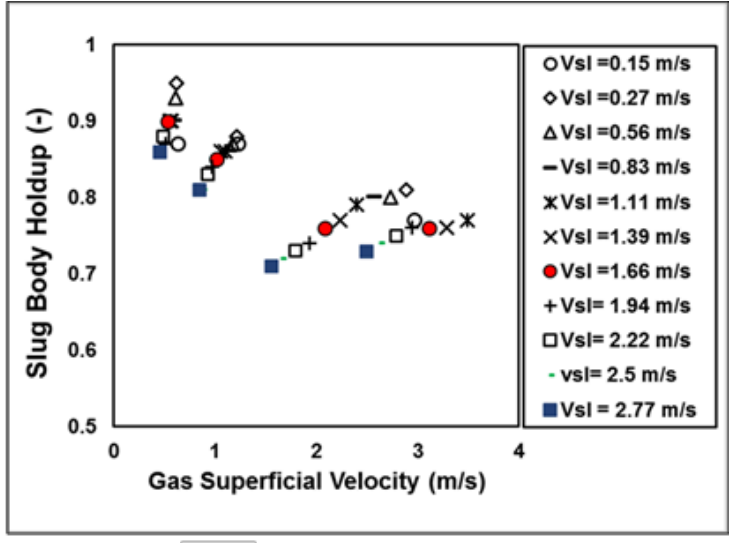

(b)

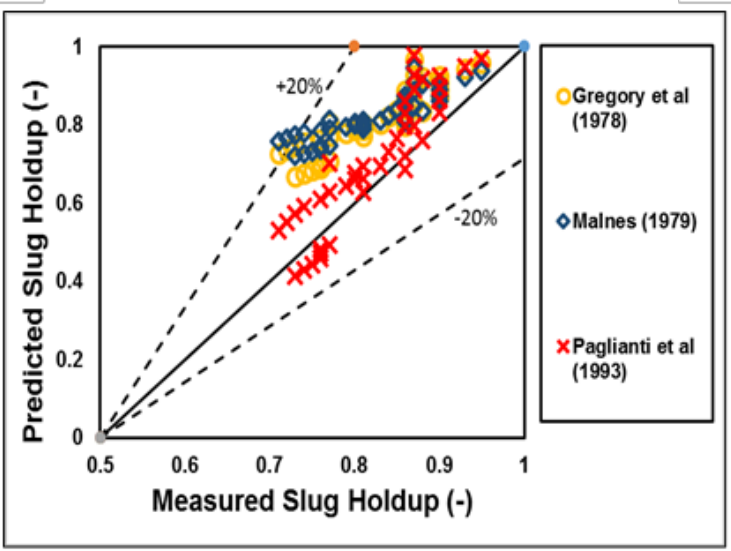

(c)

Figure 6: (a) Slug Holdup measurements at $\left(V_{S L}=0.15 \mathrm{~m} / \mathrm{s}, V_{S G}=0.63 \mathrm{~m} / \mathrm{s}\right)$; (b) Measured slug holdup as a function of gas superficial velocity in concentric annulus; (c) Comparison of slug body holdup from concentric annulus with predictive models. 


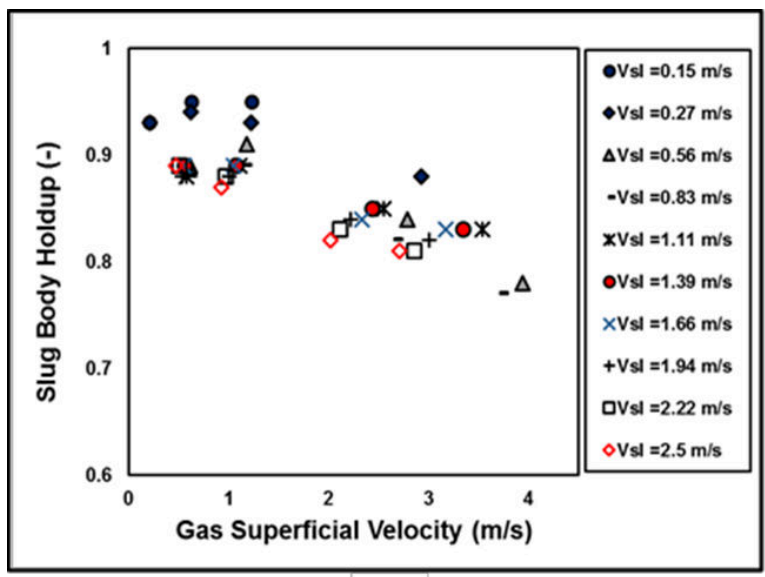

(a)

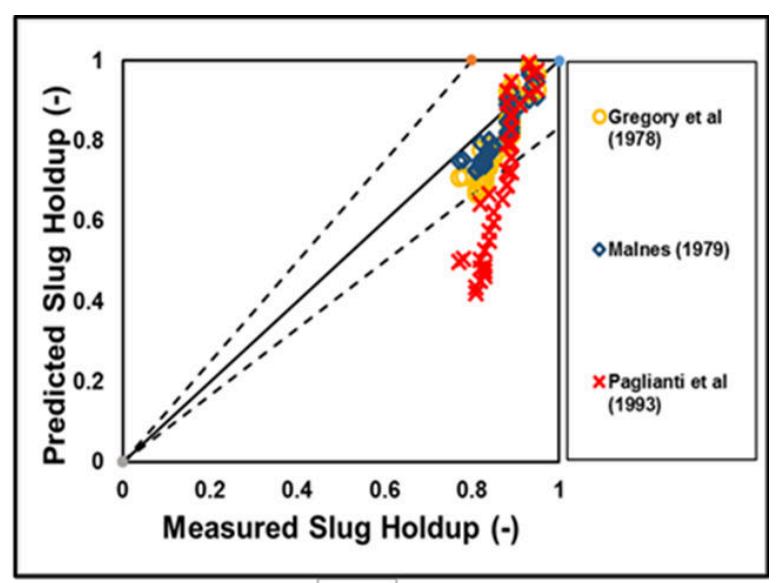

(b)

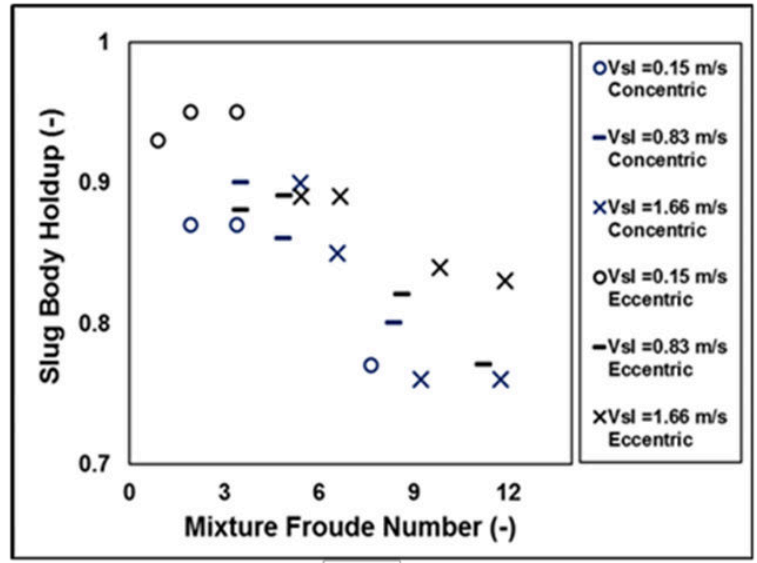

(c)

Figure 7: (a) Measured slug body holdup vs gas superficial velocity in fully eccentric annulus; (b) Comparison of slug body holdup from fully eccentric annulus with predictive models; (c) Effect of annulus eccentricity on slug body holdup. 


\section{List of Tables Captions}

Table 1: Slug frequency correlations and Strouhal number

Table 2: Extracted coefficients for slug translational velocity in horizontal concentric annulus

Table 3: Statistical results of slug body holdup performance in concentric annulus

Table 4: Statistical results of slug body holdup performance in fully eccentric annulus 
Table 5: Slug frequency correlations and Strouhal number

\begin{tabular}{|c|c|c|}
\hline Correlations & Slug frequency & Strouhal Number \\
\hline $\begin{array}{l}\text { Gregory \& } \\
\text { Scott (1969) }\end{array}$ & $v_{\text {Gregory }}=0.0226\left[\frac{V_{S L}}{g D_{H}}\left(\frac{19.75}{V_{M}}+V_{M}\right)\right]^{1}$ & $S t_{\text {Gregory }}=\frac{v * D_{H}}{V_{S G}}$ \\
\hline $\begin{array}{l}\text { Fossa et al. } \\
(2003)\end{array}$ & Experimental Data & $\begin{array}{l}S t_{(\text {Fossa })} \\
=\frac{A * X_{L}}{1+B * X_{L}+C *\left(X_{L}\right)^{2}}\end{array}$ \\
\hline $\begin{array}{l}\text { Wang et al. } \\
(2007)\end{array}$ & Experimental Data & $\begin{array}{l}S t_{(\text {Wang })} \\
=\frac{0.05 X_{L}}{1-1.675 X_{L}+0.768\left(X_{L}\right)^{2}}\end{array}$ \\
\hline $\begin{array}{l}\text { Al-Safran } \\
\text { (2016) }\end{array}$ & $\begin{array}{l}\begin{array}{rl}v_{A l-S a f r a n}=E X & P\left[1.51-17.04\left(D_{H}\right)\right. \\
& +0.77 \operatorname{Ln}\left(V_{S L}\right) \\
& -0.181 \operatorname{Ln}(S)\end{array} \\
\text { Where } S \text { is the Slip factor }\end{array}$ & $S t_{A l-\text { Safran }}=\frac{v * D_{H}}{V_{S G}}$ \\
\hline This Study & Conductance measurements & $\begin{array}{l}S t_{\text {Conductance }} \\
=\frac{v_{\text {conductance }} * D_{H}}{V_{S G}}\end{array}$ \\
\hline
\end{tabular}


Table 6: Extracted coefficients for slug translational velocity in horizontal concentric annulus

\begin{tabular}{|l|l|}
\hline Distribution Parameter $C_{0}$ & Drift Velocity $V_{d}$ \\
\hline 1.4072 & 0.2767 when $F r_{M} \leq 3.5$ \\
\hline 1.4643 & 0.2461 when $F r_{M}>3.5$ \\
\hline
\end{tabular}


Table 7: Statistical results of slug body holdup performance in concentric annulus

\begin{tabular}{|l|l|l|l|}
\hline Predictive Model & APE & AAPE & SD \\
\hline Gregory et al., ${ }^{11}$ & -1.63 & 3.98 & 4.90 \\
\hline Malnes 26 & -0.002 & 2.83 & 3.54 \\
\hline $\begin{array}{l}\text { Paglianti et al., as cited } \\
\text { on [27] }\end{array}$ & -15.3 & 16.85 & 14.6 \\
\hline
\end{tabular}


Table 8: Statistical results of slug body holdup performance in fully eccentric annulus

\begin{tabular}{|l|l|l|l|}
\hline Predictive Model & APE & AAPE & SD \\
\hline Gregory et al., 11 & -6.34 & 7.82 & 6.94 \\
\hline Malnes ${ }^{26}$ & -5.05 & 5.85 & 4.38 \\
\hline $\begin{array}{l}\text { Paglianti et al., as cited } \\
\text { on [27] }\end{array}$ & -19.2 & 20.83 & 17.60 \\
\hline
\end{tabular}

